\title{
Introduction history and species characteristics partly explain naturalization success of North American woody species in Europe
}

\author{
Anna Bucharova ${ }^{1,2,3}$ and Mark van Kleunen ${ }^{1 *}$ \\ 1/Institute of Plant Sciences and Oeschger Centre, University of Bern, Altenbergrain 21, CH-3006 Bern, Switzerland; \\ ${ }^{2}$ Municipal Museum Mariánské Lázně, Goethovo nám. 11, 35301 Mariánské Lázně, Czech Republic; and \\ ${ }^{3}$ Department of Botany, Faculty of Science, Charles University, Benátská 2, 12801 Prague, Czech Republic
}

\begin{abstract}
Summary
1. The search for general characteristics of invasive species has not been very successful yet. A reason for this could be that current invasion patterns are mainly reflecting the introduction history (i.e. time since introduction and propagule pressure) of the species. Accurate data on the introduction history are, however, rare, particularly for introduced alien species that have not established. As a consequence, few studies that tested for the effects of species characteristics on invasiveness corrected for introduction history.

2. We tested whether the naturalization success of 582 North American woody species in Europe, measured as the proportion of European geographic regions in which each species is established, can be explained by their introduction history. For 278 of these species we had data on characteristics related to growth form, life cycle, growth, fecundity and environmental tolerance. We tested whether naturalization success can be further explained by these characteristics. In addition, we tested whether the effects of species characteristics differ between growth forms.

3. Both planting frequency in European gardens and time since introduction significantly increased naturalization success, but the effect of the latter was relatively weak. After correction for introduction history and taxonomy, six of the 26 species characteristics had significant effects on naturalization success. Leaf retention and precipitation tolerance increased naturalization success. Tree species were only $56 \%$ as likely to naturalize as non-tree species (vines, shrubs and subshrubs), and the effect of planting frequency on naturalization success was much stronger for non-trees than for trees. On the other hand, the naturalization success of trees, but not for non-trees, increased with native range size, maximum plant height and seed spread rate.

4. Synthesis. Our results suggest that introduction history, particularly planting frequency, is an important determinant of current naturalization success of North American woody species (particularly of non-trees) in Europe. Therefore, studies comparing naturalization success among species should correct for introduction history. Species characteristics are also significant determinants of naturalization success, but their effects may differ between growth forms.
\end{abstract}

Key-words: alien species, establishment, exotic species, introduced species, introduction effort, non-indigenous, propagule pressure, species traits, time since introduction

\section{Introduction}

Biological invasions are recognized as one of the greatest threats to the ecological well-being of our planet (Drake $e t \mathrm{al}$. 1989; Vitousek et al. 1997), and also cause large economic costs (Pimentel et al. 2000). To counteract current invasions and to

*Correspondence author. E-mail: vkleunen@ips.unibe.ch prevent new invasions, we need to unravel the determinants of invasiveness. Although many hypotheses on the causes of biological invasions have been postulated, and research on biological invasions has strongly increased during the last couple of decades (Richardson \& Pyšek 2008), few traits have been identified that consistently distinguish successful invaders from non-invaders (Nentwig 2007; Pyšek \& Richardson 2007; van Kleunen \& Richardson 2007; Moles et al. 2008). 
It has frequently been suggested that current invasion patterns are mainly determined by the introduction history of the species, including the time since introduction (Pyšek \& Jarošik 2005) and introduction effort (i.e. propagule pressure, Williamson 1996; Lockwood et al. 2005; Colautti et al. 2006). With a few exceptions (Mulvaney 2001; Cassey et al. 2005; Křivánek et al. 2006; Dehnen-Schmutz et al. 2007a,b), accurate data on the introduction history of large groups of species, particularly of species that failed to establish, are rare. As a consequence, most studies that tested or accounted for the role of time since introduction used minimum residence time, which frequently is not based on the first year of introduction but on the earliest record of establishment in the wild (e.g. Kareiva et al. 1996; Pyšek et al. 2003; Hamilton et al. 2005; Pyšek \& Jarošik 2005; Milbau \& Stout 2008). However, because widely naturalized alien species are more likely to be noted and collected by botanists than simultaneously introduced species that did not establish, most estimates of minimum residence time have an inherent positive relationship with naturalization success. Similarly, the few studies that tested for or accounted for the role of propagule pressure often used very crude proxies such as human use of the species (e.g. Thuiller et al. 2006) and size of the native range (e.g. Forcella \& Wood 1984). Due to the lack of accurate data it has been difficult to assess whether introduction history is really the main driver of invasiveness.

It has been suggested that successful weeds or invasive plants should possess characteristics such as a fast life cycle, rapid growth, tall stature, high fecundity and a high environmental tolerance (e.g. Baker 1974). Although some studies have shown that a high fecundity is consistently associated with invasiveness, evidence for the role of other characteristics is still limited (Pyšek \& Richardson 2007). One of the potential reasons why few species characteristics have been found to be consistently associated with establishment success is that many studies did not account for introduction history or used very crude proxies. Introduction history of species may obscure the effects of species characteristics and may be confounded with species characteristics (Pyšek et al. 2003; Alpert 2006; Colautti et al. 2006). Such confounding might happen, for instance, when early-introduced species and late-introduced species have different characteristics. Therefore, accurate data on the introduction history of species are required when testing for effects of species characteristics on invasiveness. Dehnen-Schmutz et al. $(2007 \mathrm{a}, \mathrm{b})$ showed that, after correction for introduction history, species characteristics, such as size of the plant's native range and growth form, affected the establishment success of ornamental plants in Great Britain. We are aware of no other studies that had relatively accurate data on introduction history of plant species and tested for the effect of species characteristics on naturalization success.

Another potential reason why few species characteristics have been found to be consistently associated with establishment success is that the importance of species characteristics might be context-dependent (Pyšek \& Jarošik 2005). For example, Herron et al. (2007) found that while wind dispersal is positively associated with invasiveness of trees in New England, it is negatively associated with invasiveness of shrubs and vines. To the best of our knowledge, hardly any other studies (but see Küster et al. 2008) have tested whether the effects of species characteristics depend on growth form.

We tested whether the naturalization success of 582 North American woody species in Europe, measured as the proportion of European geographic regions in which each species is established (i.e. has formed self-reproducing populations), can be explained by their introduction history. For 278 of these species we had data on characteristics related to growth form, life cycle, growth, fecundity and environmental tolerance, and for them we tested whether naturalization success can be explained by these characteristics. In addition, we tested whether the effects of species characteristics differ between growth forms.

\section{Methods}

\section{COMPILATION OF DATA SET}

The basis for our data set is a list of woody species introduced into European gardens and parks since the 16th century (Goeze 1916). Although this list contains species native to many different continents, we restricted our data set to species from North America (USA and Canada), because for a large number of these species data on potentially relevant characteristics were available. For most species on the list, Goeze (1916) includes the year of earliest record in European gardens. We updated and expanded this species list with data from Wein (1930, 1931). For the resulting list of 793 woody species, we validated the origin and taxonomic status of the species by using several internet data bases (Flora Europaea, http://rbg-web2.rbge.org.uk/FE/fe.html; USDA PLANTS data base, http://plants.usda.gov; Germplasm Resources Information Network data base, http://www.ars-grin.gov; Plants for a Future, http://www.pfaf.org). For 211 species, we could neither identify the current taxonomic status nor confirm that they originate from North America. As a consequence, the final data set contained 582 instead of 793 species.

For each of the 582 North American woody species with known year of introduction to Europe, we added as an estimate of introduction effort (i.e. propagule pressure) the number of European parks, arboreta and botanical gardens, where the species was planted (hereafter referred to as planting frequency) from Bartels et al. (1982). This list covers the following countries (number of gardens): Austria (16), Belgium (3), Bulgaria (1), Czechoslovakia (30), Denmark (3), East Germany (5), Finland (5), France (4), Hungary (4), the Netherlands (10), Norway (2), Poland (5), Rumania (1), Sweden (4), Switzerland (8), West Germany (96) and Yugoslavia (3). For each of the plant species, as a measure of naturalization success, we assessed the number of European geographic regions in which the species is established from the recently completed DAISIE data base (http://www.europe-aliens.org/; Lambdon et al. 2008). This data base covers 52 geographic regions, most of which correspond to countries in Europe, but some of which (e.g. Corsica) are islands within countries, and one of which (Israel) is a non-European country. The number of occupied geographic regions is a crude estimate of the naturalized range size of a species, because it does not account for the local abundance of species. However, for the 51 species in our data set that have established in Germany, the number of European geographic regions occupied by a species correlates positively (Spearman's $\rho=0.681, P<0.001$ ) with the 
Table 1. The initial set of explanatory variables used in the analysis of the 278 North American woody species for which we had complete data. The variables in bold were included in the minimum adequate model (see Table 2)

\begin{tabular}{|c|c|c|}
\hline Variable & Units or categories & Source \\
\hline \multicolumn{3}{|l|}{ Introduction history } \\
\hline Time since introduction & Years & Goeze 1916; Wein 1930, 1931 \\
\hline Planting frequency & Number of European gardens & Bartels et al. 1982 \\
\hline \multicolumn{3}{|l|}{ Taxonomy } \\
\hline Family & 50 families & USDA Plants \\
\hline \multicolumn{3}{|l|}{ Species characteristics } \\
\hline Growth form* & & USDA Plants \\
\hline Tree & Yes, no & \\
\hline Vine & Yes, no & \\
\hline Shrub & Yes, no & \\
\hline Subshrub & Yes, no & \\
\hline Native range size & $\begin{array}{l}\text { Number of US states and } \\
\text { Canadian Provinces and Territories }\end{array}$ & USDA Plants \\
\hline Length of annual growth period & Number of seasons & USDA Plants \\
\hline $\mathrm{CaCO}_{3}$ tolerance & None, low, medium, high & USDA Plants \\
\hline Average pH & $\mathrm{pH}$ units & USDA Plants \\
\hline $\mathrm{pH}$ tolerance & Range of $\mathrm{pH}$ units & USDA Plants \\
\hline Soil fertility requirement & Low, medium, high & USDA Plants \\
\hline Fire tolerance & None, low, medium, high & USDA Plants \\
\hline Salinity tolerance & None, low, medium, high & USDA Plants \\
\hline Shade tolerance & Low, medium, high & USDA Plants \\
\hline Drought tolerance & Low, medium, high & USDA Plants \\
\hline Average precipitation & Inches of annual rainfall & USDA Plants \\
\hline Precipitation tolerance & Range of annual rainfall & USDA Plants \\
\hline Minimum tolerable temperature & Degrees Fahrenheit & USDA Plants \\
\hline Annual frost-free period & Minimum number of frost-free days per year & USDA Plants \\
\hline Average temperature preference & Mean of hardiness range & Cheers et al. 2004a,b \\
\hline Temperature tolerance & Range of hardiness zones $(1-12)$ & Cheers et al. 2004a,b \\
\hline Life span & $\begin{array}{l}\text { Short, moderate, long relative } \\
\text { to other species of same growth form }\end{array}$ & USDA Plants \\
\hline Leaf retention & Evergreen, deciduous & USDA Plants \\
\hline Maximum plant height & Meters & USDA Plants, Cheers et al. 2004a,b \\
\hline Growth rate & $\begin{array}{l}\text { Slow, moderate, rapid relative } \\
\text { to other species of same growth form }\end{array}$ & USDA Plants \\
\hline Fruit and seed abundance & $\begin{array}{l}\text { Low, moderate, high relative } \\
\text { to other species of same growth form }\end{array}$ & USDA Plants \\
\hline Seed mass & Average mass of 1000 seeds in grams & USDA Plants, Flynn et al. 2006 \\
\hline Seedling vigour & $\begin{array}{l}\text { Low, medium, high relative } \\
\text { to other species of same growth form }\end{array}$ & USDA Plants \\
\hline Seed spread rate & $\begin{array}{l}\text { Slow, fast relative to other species } \\
\text { of same growth form }\end{array}$ & USDA Plants \\
\hline Vegetative spread rate & $\begin{array}{l}\text { None, slow, moderate, rapid relative } \\
\text { to other species of same growth form }\end{array}$ & USDA Plants \\
\hline
\end{tabular}

*Instead of using growth form as a multinomial variable, we included the categories as binomial variables, which are easier to interpret.

number of $10^{\prime}$ longitude $\times 6^{\prime}$ latitude grid cells occupied in Germany (http://www.floraweb.de). This indicates that our measure of naturalization success is robust.

For each species, we collated data on 26 species characteristics that we considered potentially relevant for naturalization success from the USDA PLANTS data base (http://plants.usda.gov), the Seed Information data base (http://www.kew.org/data/sid; Flynn et al. 2006) and two horticultural encyclopaedia (Cheers 2004a,b). The USDA PLANTS data base provides information on 86 characteristics, mainly derived from grey literature and expert opinions. For our analysis, we only considered those characteristics that could be biologically relevant, and were not highly auto-correlated. The 26 species characteristics were mainly related to growth form, life cycle, growth, fecundity and tolerance to climatic and edaphic factors
(Table 1). Because information on these characteristics was not available for about half of the species, this data set included 278 instead of 582 species with complete information. This subset of species comprised almost the same range of years of introduction (1536-1910) as the complete data set (1536-1915). Overall, however, the species in the subset had been introduced earlier (median year of introduction $=1765)$ than the species not included in the subset (median year of introduction $=1819$; Mann-Whitney $U=32341$, $P<0.001)$.

\section{STATISTICAL ANALYSIS}

To test whether the introduction history and species characteristics have determined the current naturalization success of North American 
woody species in Europe, we used stepwise logistic regression implemented in the statistical software Genstat, 9th edition (Payne et al. 2005). We used logistic regression instead of normal regression, because the data on establishment in European geographic regions were highly skewed due to the large number of introduced species that had not established in any region (i.e. there were many zeroes in the data set). In all analyses, the binomial response variable was the number of European geographic regions in which the species has established populations. The binomial total was set to 52 , which equals the number of European geographic regions covered by the DAISIE data base for terrestrial plants. Effectively, this means that we analysed the proportion of European geographic regions in which the species is established.

Because we had complete data on the introduction history of 582 species, but the biological species characteristics for only 278 species, we performed two separate analyses. In the first analysis, we included all 582 species, 98 of which are successfully established in at least one European geographic region, to test for the effects of the two components of a species' introduction history, time since introduction and planting frequency (i.e. propagule pressure), and the components' interaction effect on naturalization success. In the second analysis, we included the 278 species for which we had complete information on the 26 available characteristics (Table 1) and tested for the effects of these characteristics and their interactions with growth form on naturalization success. Seventy-two of these 278 species are successfully established in at least one European geographic region. Because we had a large set of explanatory variables for this analysis, we searched for the minimal adequate model that includes only significant explanatory variables and interactions (e.g. Krrivánek et al. 2006). We largely followed the procedure recommended by Hosmer \& Lemeshow (2000). First, we performed univariable logistic regressions for all explanatory variables. Second, all explanatory variables that had a $P<0.25$ in the univariable logistic regressions were included into multivariable models. We used Akaike's Information Criterion (AIC) to select from all possible multivariable models with up to 16 terms (i.e. the limit of the RSEARCH procedure in Genstat) the best model (i.e. the one that provided maximum fit for the fewest numbers of explanatory variables). Each variable was afterwards removed one-byone to determine whether removal of the variable resulted in a statistically significant change in deviance of the model. To this aim we calculated ratios of mean deviance changes (quasi $F$-values), which approximately follow the $F$-distribution (Payne $e t$ al. 2005). Thereafter, we tested for interactions between growth form (trees and non-trees) and the remaining terms, except for family. In the minimum adequate model, we only kept interactions that were statistically significant $(P<0.05)$.

In the final model, we first fitted the planting frequency followed by family to correct all subsequent terms for introduction history and taxonomy. Time since introduction was not included in the final model, because it had no significant effect on naturalization success in this analysis. Subsequently, we fitted the growth form followed by the other main terms of the species characteristics. Growth form was fitted before the other terms to correct for the fact that some of the species characteristics were measured relative to other species with the same growth form (Table 1). Furthermore, to correct for potential correlations among the species characteristics, we ran the logistic regressions several times in such a way that each of the characteristics was fitted last. This is similar to using type III sums of squares in ANOVA, and means that we used conservative estimates of the effects of species characteristics, apart from growth form, on establishment success. Finally, we added the interaction terms by first fitting the growth-form-by-planting-frequency interaction followed by the other ones. Again, we ran the logistic regression several times in such a way that each of the interactions was fitted last.

For each term in the final model, we calculated the odds-ratio and its $95 \%$ confidence interval $(95 \% \mathrm{CI})$ to determine how the probability of naturalization increases (odds-ratio $>1$ ) or decreases (odds-ratio $<1$ ) when the predictor variable increases by one unit. Analogous to the coefficient of determination in ANOVA, we calculated the likelihood ratio $R^{2}$ of each model as the deviance explained by the model divided by total deviance (Menard 2000).

\section{Results}

\section{EFFECT OF INTRODUCTION HISTORY ON NATURALIZATION SUCCESS}

In the analysis of the 582 North American woody species, both time since introduction (odds-ratio $=1.006,95 \%$ $\mathrm{CI}=1.003-1.009$, Quasi- $\left.F_{1.578}=19.67, P<0.001\right)$ and planting frequency (odds-ratio $=1.025,95 \% \mathrm{CI}=1.023-1.028$, Quasi- $\left.F_{1.578}=366.96, P<0.001\right)$ significantly increased the probability of naturalization of the species in European geographic regions. The interaction between the two variables was not significant (Quasi- $F_{1,578}=3.29, P=0.070$ ). $R^{2}$, the likelihood ratio, of the model was 0.47 , and planting frequency, when fitted first, explained $45 \%$ of the total deviance, while time since introduction, when fitted first, explained $13 \%$ of the total deviance.

\section{EFFECTS OF SPECIES CHARACTERISTICS ON NATURALIZATION SUCCESS}

In the analysis of the 278 North American woody species subset the minimum adequate model included six species characteristics and four interaction terms (Table 2). This model also included planting frequency and family to correct for introduction history and taxonomy, respectively. Planting frequency had a significant positive effect on naturalization success, and the 50 families represented in our data set varied significantly in their naturalization success (Table 2). The families with most successful species were the Urticaceae (odds-ratio $=5.87$; reference family for the odds-ratios is the Aceraceae), Vitaceae (odds-ratio $=3.60$ ) and Asteraceae (odds-ratio $=3.55$ ). The families with no successful species were the Styracaceae (odds-ratio $=0.00005$ ), Clethraceae (oddsratio $=0.00006)$ and Tiliaceae (odds-ratio $=0.00008) \cdot R^{2}$ was 0.78 , indicating that the model explained most of the variation in naturalization success.

The minimum adequate model included only the growth form categories 'tree' $(n=192)$ and 'non-tree' $(n=86)$, because the model-building procedure revealed no significant differences between vines, shrubs and subshrubs. The likelihood of naturalization in a European geographic region was lower for tree species (median proportion of European geographic regions $=0.0096$ ) than for non-tree species (median proportion of European geographic regions $=0.0169$; Table 2) . Independent of growth form, the likelihood of naturalization was higher for evergreen species (median proportion of European geographic regions $=0.0188, n=87$ ) than for deciduous species 
Table 2. Summary of logistic regression of number of European geographic regions (binomial total $=52$ ) where 278 North American woody species have successfully established for the minimal adequate model. The residual deviance (d.f. $=217)$ and total deviance were 295.95 and 1324.84, respectively. Change in deviance for each variable (effect) included in the minimum adequate model, except for planting frequency, family and growth form, is from a model with this variable fitted as the last one

\begin{tabular}{|c|c|c|c|c|c|}
\hline Effect & Odds ratio $(95 \% \mathrm{CI})$ & d.f. & Change in deviance & Quasi- $F$ & $P$-value \\
\hline Planting frequency & $1.025(1.021-1.029)$ & 1 & 554.66 & 406.70 & $<0.001$ \\
\hline Family & & 49 & 260.01 & 3.89 & $<0.001$ \\
\hline Growth form (trees vs. non-trees) & $0.560(0.313-1.002)$ & 1 & 8.67 & 6.36 & 0.012 \\
\hline Native range size & $1.055(1.036-1.075)$ & 1 & 60.80 & 44.56 & $<0.001$ \\
\hline Precipitation tolerance & $1.015(1.009-1.021)$ & 1 & 35.38 & 25.94 & $<0.001$ \\
\hline Maximum plant height & $1.022(1.005-1.039)$ & 1 & 10.46 & 7.67 & 0.006 \\
\hline Seed spread rate & $2.064(1.392-3.062)$ & 1 & 22.02 & 16.15 & $<0.001$ \\
\hline Leaf retention & $3.240(1.337-7.861)$ & 1 & 11.08 & 8.12 & 0.005 \\
\hline Growth form $\times$ planting frequency & $0.990(0.982-0.998)$ & 1 & 10.90 & 7.99 & 0.005 \\
\hline Growth form $\times$ native range size & $1.071(1.038-1.106)$ & 1 & 24.48 & 17.95 & $<0.001$ \\
\hline Growth form $\times$ maximum plant height & $1.199(0.976-1.472)$ & 1 & 6.61 & 4.85 & 0.029 \\
\hline Growth form $\times$ seed spread rate & $10.510(4.141-26.656)$ & 1 & 34.91 & 25.60 & $<0.001$ \\
\hline
\end{tabular}

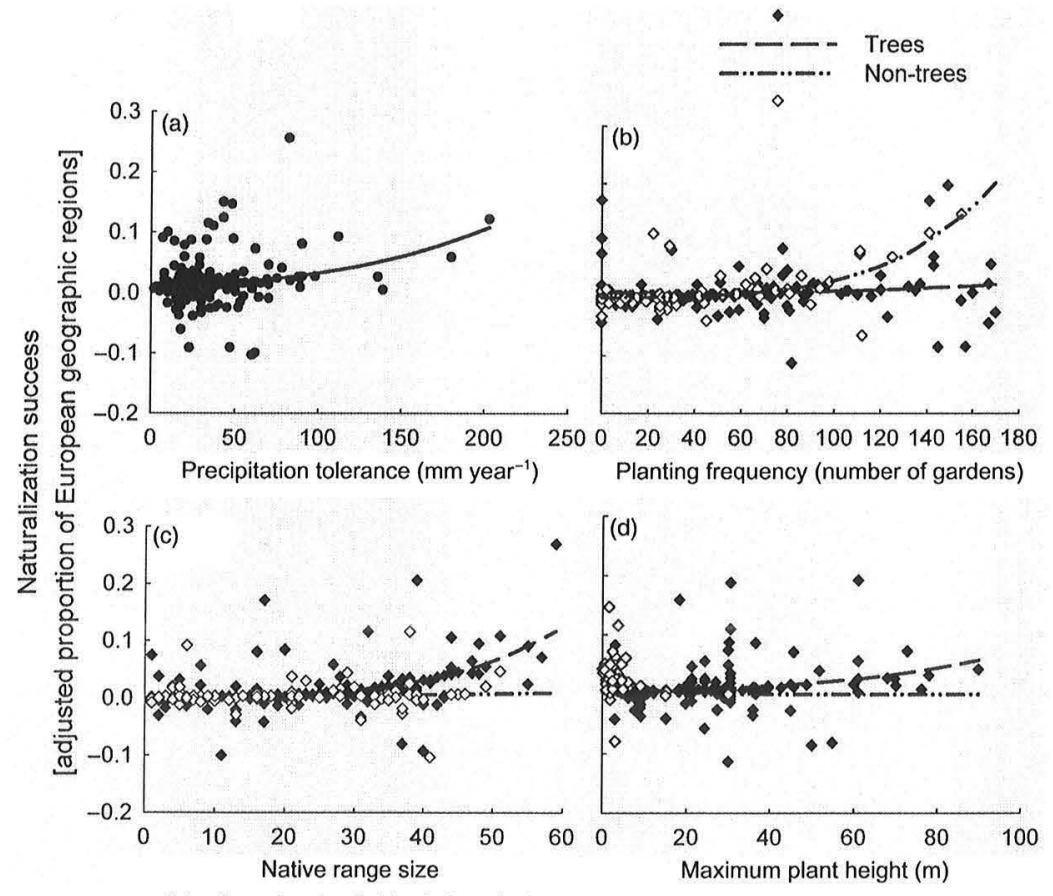

(Number of states in North America)
Fig. 1. Naturalization success of 278 North American woody species as a function of (a) precipitation tolerance (i.e. the range of precipitation tolerated by the species in North America), (b) planting frequency in gardens, (c) native range size and (d) maximum plant height. For the last three variables (b-d), the strength of the association depended on the growth form of the species. Naturalization success of each species was measured as the number of European geographic regions in which it is established. The proportion values of precipitation tolerance were adjusted for the other main effects in the model, and the proportion values of planting frequency, native range size and maximum plant height were also adjusted for the interactions in the model. The lines are the fitted relationships from logistic regressions. (median proportion of European geographic regions $=0.0050$, $n=192$; Table 2). Furthermore, precipitation tolerance significantly increased the naturalization success of species (Fig. 1, Table 2).

Native range size, maximum plant height and seed spread rate also significantly increased the naturalization success of species (Table 2). However, as indicated by the significant interaction term (Table 2), the effect of seed spread rate on naturalization success was strongly positive for tree species (median proportion of European geographic regions for trees with a slow seed spread rate $=0.0039, n=140$; median proportion of European geographic regions for trees with a fast seed spread rate $=0.0189, n=52$ ), while it tended to be slightly negative for non-tree species (median proportion of European geographic regions for non-trees with a slow seed spread rate $=0.0039, n=66$; median proportion of European geographic regions for non-trees with a fast seed spread rate $=$ $0.0021, n=20$ ). Similarly, the effects of native range size and maximum plant height were much stronger for tree species than for non-tree species (Fig. 1). On the other hand, the positive effect of planting frequency on naturalization success was much stronger for non-tree species than for tree species (Fig. 1). These results indicate that the determinants of naturalization success differ between growth forms. 


\section{Discussion}

\section{INTRODUCTION HISTORY}

Introduction history is frequently mentioned as one of the major determinants of the current invasiveness status of alien plants (Williamson 1996; Lockwood et al. 2005; Pyšek \& Jarošik 2005; Colautti 2005). However, few studies included reasonably accurate data on both the time since introduction (i.e. in contrast to the time since first record in the wild, which is frequently used) and propagule pressure (Mulvaney 2001; Křivánek et al. 2006; Dehnen-Schmutz et al. 2007a,b) to test this. In our study, time since introduction and, particularly, planting frequency (i.e. propagule pressure) determined the current degree of naturalization of North American woody plants in Europe. Similar results were found for 289 ornamental woody species in south-eastern Australia (Mulvaney 2001), and for 28 alien tree species planted for forestry purposes in the Czech Republic (Křivánek et al. 2006). Although these results do not unambiguously prove it, they at least strongly suggest that the introduction history determines the current invasiveness status of alien species rather than that species with high invasion potential happen to have been earlier or more widely planted than species without invasion potential. This implies that studies comparing invasiveness of species should account for introduction history.

In our study system planting frequency explained more of the variation in naturalization success than time since introduction. A potential reason for the relatively small effect of time since introduction could be that our data set included only species that had been introduced to Europe before 1915 . Although the species might not have spread to their full potential yet, it is likely that time since introduction would have been more important as determinant of current naturalization success if our data set had also included more recently introduced species. In line with this, time since introduction did not significantly determine naturalization success in the subset of species used to test the effects of species characteristics, and in which late-introduced species were even less represented than in the complete data set (see Methods).

\section{SPECIES CHARACTERISTICS}

Six of the 26 species characteristics we studied had a significant effect on naturalization success, although they only explained a relatively small percentage ( $16.3 \%$ vs. $61.4 \%$ for introduction history and taxonomy) of the variation in naturalization success. Nevertheless, their significance implies that if we were to simultaneously introduce two or more species of the same family at equal frequencies, their characteristics would at least in part determine their naturalization success.

Tree species had a lower naturalization success in Europe than non-tree species (i.e. vines, shrubs and subshrubs). A similar result was found for 165 woody species introduced into New England (Herron et al. 2007). A potential explanation for the low naturalization success of trees could be that they are less frequently used as ornamentals than non-trees. Another potential explanation could be that trees usually have longer juvenile periods than non-trees, and as a consequence require more time before they can reproduce and spread. This is consistent with the findings of Rejmánek \& Richardson (1996) that invasive Pinus species have shorter juvenile periods than non-invasive ones.

Most interestingly, the positive effect of planting frequency on naturalization success was much smaller for trees than for non-trees. This could be because some of the tree species that are not planted frequently in gardens, but have naturalized, are used in forestry (Křivánek et al. 2006). It could also be that many of the naturalized tree species were introduced to the UK, which has a strong horticultural tradition, but was not covered by our source for planting frequency (Bartels et al. 1982). Another explanation could be that gardens usually contain fewer individuals of each tree species than of non-trees. Despite their larger potential seed output, trees might thus rarely reproduce due to mate limitation. The presence of trees and non-trees in the same number of gardens may therefore not reflect the same propagule pressure.

Evergreen species had a higher naturalization success in Europe than deciduous species. This pattern could reflect the successful naturalization of many coniferous species (Richardson \& Rejmánek 2004), and the successful establishment of evergreen broad-leaved woody plants in the Mediterranean parts of Europe. Also at higher latitudes, shrub layers have become increasingly dominated by alien evergreen broadleaved species - possibly as a consequence of climate change (Walther et al. 2002). In contrast, for North America the evergreen woody species are less likely to become invasive (Reichard \& Hamilton 1997; Herron et al. 2007). Although the biological reason for these different patterns remains obscure, they indicate that the importance of leaf retention for invasiveness of woody species is continent-specific.

Environmental tolerance of species is probably a strong determinant of naturalization success (Baker 1974; Richards et al. 2006). In line with this, the woody species occurring over a wide precipitation gradient in North America had a higher naturalization success in Europe than the species that occur over a narrow precipitation gradient in North America. Although many other species characteristics in our data set are directly related to environmental tolerance, none had a significant effect on naturalization success. Nevertheless, the positive effect of precipitation tolerance supports the hypothesis that environmental tolerance increases invasiveness (Baker 1974; Richards et al. 2006).

Size of the native range may indirectly reflect environmental tolerance of the species (Scott \& Panetta 1993; Goodwin et al. 1999; Prinzing et al. 2002). However, wide-spread species may also have a higher chance of being encountered by horticulturalists and being selected for introduction elsewhere than species with a small native range (Pyšek et al. 2004). Van Kleunen et al. (2007) showed that the probability of southern African Iridaceae to be introduced elsewhere for horticultural purposes was positively associated with native range size, but that subsequent naturalization of these species was not associated with size of the native range. This suggests that size 
of the native range mainly reflects the chance of being introduced elsewhere. In our study, however, because we directly corrected for planting frequency in our analysis, the remaining variation in naturalization success explained by size of the native range most likely reflects some component of environmental tolerance that was not covered by the other species characteristics in our data set (e.g. tolerance to herbivores and pathogens).

Although naturalization success was positively associated with size of the native range, this pattern was mainly accounted for by the trees in our data set. Most previous studies also revealed positive associations between invasiveness and size of the native range (Forcella \& Wood 1984; Scott \& Panetta 1993; Rejmánek 1995, 1996; Goodwin et al. 1999; Prinzing et al. 2002; but see Milbau \& Stout 2008 for an exception). To the best of our knowledge, however, none of these previous studies showed that this association differs between growth forms.

One of the potential characteristics of invasive species is rapid growth (Baker 1974). Our study did, however, not reveal a significant association between growth rate and naturalization success of North American woody species in Europe. This could be because the estimates of growth rate were semi-quantitative (slow, moderate and fast). Nevertheless, two previous studies that used the same data source for growth rate as we did found that invasiveness of woody species is positively associated with growth rate (Frappier \& Eckert 2003; Herron et al. 2007). Of the few studies that used experimentally determined relative growth rates of alien woody species, Bellingham et al. (2004) found no significant association between growth rate of seedlings and invasiveness, but Grotkopp et al. (2002) and Grotkopp \& Rejmánek (2007) found a significant association. So, although invasiveness of woody species is frequently associated with rapid growth, this did not appear to be the case for North American woody species in Europe. Clearly, experimentally determined estimates of growth rate are needed to test whether this also holds when more accurate data are used.

Competitiveness of plants is likely to increase with size (Pianka 1970), and therefore it has often been suggested that plant size may promote naturalization of a species (Crawley 1987; Blossey \& Nötzold 1995). This is consistent with our finding that naturalization was positively associated with plant height, although this positive association was only present among the tree species in our data set. On the other hand, the invasiveness of alien woody species in New England is not significantly associated with mature plant height (Herron et al. 2007). Overall, it seems that the association between invasiveness and plant height depends on the growth form of the species and the target region, but in the studies that found an association it was always a positive one.

Dispersal characteristics are likely to be important determinants of spread of alien species (Baker 1974). As expected, seed spread rate was positively associated with naturalization success in Europe. However, again this positive association was present among the tree species in our data set but not among the non-tree species. Similarly, Herron et al. (2007) found that wind dispersal was positively associated with invasiveness of trees in New England but was not associated with invasiveness of non-trees. Together these results suggest that seed dispersal characteristics are determinants of invasiveness of trees but not of invasiveness of other woody species.

\section{CONCLUSIONS}

A major aim in invasion biology is the identification of species characteristics that determine invasiveness. Although the number of studies comparing species with different degrees of invasiveness is increasing, their overall number is still low (Pyšek \& Richardson 2007), and very few studies have included introduced species that failed to establish (e.g. DehnenSchmutz et al. 2007a,b; van Kleunen et al. 2007) or corrected for both time since introduction and propagule pressure. Our study showed that the current naturalization success of North American woody species in Europe is mainly determined by their introduction history, particularly planting frequency. This implies that many of the species that have been introduced recently or at low frequency might not have reached their full invasion potential yet, and therefore should not be ignored by conservation authorities.

Although a large proportion of the variation in naturalization success was explained by introduction history, species characteristics related to environmental tolerance, plant size, dispersal and growth form also contributed significantly to naturalization success of North American woody species in Europe. This implies that these traits are good candidates to be used in screening procedures for predicting potential naturalization success of woody species considered for introduction. It also shows, however, that even species that do not possess the optimal suite of characteristics might eventually establish when planted frequently.

For several characteristics the available data were very crude, and for other potentially important traits no data were available. Therefore, the explanatory power of species characteristics might further increase when more accurate data and data on larger numbers of species characteristics become available. Many of these characteristics, such as breeding system, phenotypic plasticity and competitive ability, will have to be assessed experimentally (van Kleunen \& Johnson 2007; van Kleunen \& Richardson 2007; van Kleunen et al. 2008).

Another important finding of our study is that the strength of the association between species characteristics strongly depends on the growth form of the species. This shows that the importance of some species characteristics cannot be generalized for all growth forms, and that it is crucial to test for interactions between growth form and other characteristics, when searching for determinants of invasiveness.

\section{Acknowledgements}

Authors thank Silvia Zingg for digitalizing data, and Peter Alpert, Petr Pyšek and two anonymous referees for valuable comments on a previous version of 
the manuscript. A.B. acknowledges funding from Mobility Fond of Charles University, Foundation of Josef, Marie and Zdenka Hlávkových and the National Centre of Competence in Research - Plant Survival for her stay at the University of Bern.

\section{References}

Alpert, P. (2006) The advantages and disadvantages of being introduced. Biological Invasions, 8, 1523-1534.

Baker, H.G. (1974) The evolution of weeds. Annual Review of Ecology and Systematics, 5, 1-24

Bartels, H., Bärtels, A., Schroeder, F.G. \& Seehann, G. (1982) Erhebung über das Vorkommmen winterharter Freilandgehölze. II Gie Gehölze mit ihrer Verbreitung in den Gärten und Parks. Mitteilungen der Deutschen Dendrologischen Gesellschaft, 74, 1-377 (in German).

Bellingham, P.J., Duncan, R.P., Lee, W.G. \& Buxton, R.P. (2004) Seedling growth rate and survival do not predict invasiveness in naturalized woody plants in New Zealand. Oikos, 106, 308-316.

Blossey, B. \& Nötzold, R. (1995) Evolution of increased competitive ability in invasive nonindigenous plants: a hypothesis. Journal of Ecology, 83, 887-889.

Cassey, P., Blackburn, T.M., Duncan, R.P. \& Lockwood, J.L. (2005) Lessons from the establishment of exotic species: a meta-analytical case study using birds. Journal of Animal Ecology, 74, 250-258.

Cheers, G. (ed.) (2004a) Flora - a Gardener's Encyclopedia. Timber Press, Portland

Cheers, G. (ed.) (2004b) Botanica - the Illustrated A-Z of Over 10000 Garden Plants. Random House Australia Pty Ldt, Milsons Point.

Colautti, R.I. (2005) Are characteristics of introduced salmonid fishes biased by propagule pressure? Canadian Journal of Fishery and Aquatic Sciences. 62, 950-959.

Colautti, R.I., Grigorovich, I.A. \& MacIsaac, H.J. (2006) Propagule pressure: a null model for biological invasions. Biological Invasions, 8, 1023-1037.

Crawley, M.J. (1987) What makes a community invasible? Colonization, Succession and Stability (eds A.J. Gray, M.J. Crawley \& P.J. Edwards), pp. 429-453. Blackwell Science, Oxford.

Dehnen-Schmutz, K., Touza, J., Perrings, C. \& Williamson, M. (2007a) The horticultural trade and ornamental plant invasions in Britain. Conservation Biology, 21, 224-231.

Dehnen-Schmutz, K., Touza, J., Perrings, C. \& Williamson, M. (2007b) A cent ury of the ornamental plant trade and its impact on invasion success. Diversity and Distributions, 13, 527-534.

Drake, J.A., Mooney, H.A., di Castri, F., Groves, R.H., Kruger, F.J., Rejmánek, M. \& Williamson, M., eds (1989) Biological Invasions: a Global Perspective. Wiley and Sons, New York.

Flynn, S., Turner, R.M. \& Stuppy, W.H. (2006) Seed Information Database. Release 7.0. Freely accessible at http://www.kew.org/data/sid.

Forcella, F. \& Wood, J.T. (1984) Colonization potentials of alien weeds are related to their native distributions: implications for plant quarantine. Journal of the Australian Institute of Agricultural Science, 50, 35-40.

Frappier, B. \& Eckert, R.T. (2003) Utilizing the USDA PLANTS database to predict exotic woody plant invasiveness in New Hampshire. Forest Ecology and Management, 185, 207-215.

Goeze, E. (1916) Liste der seit dem 16. Jahrhundert eigenführten Bäume und Sträucher. Mitteilungen der Deutschen Dendrologischen Gesellschaft, 25, 129-201 (in German).

Goodwin, B.J., McAllister, A.J. \& Fahrig, L. (1999) Predicting invasiveness of plant species based on biological information. Conservation Biology, 13, 422-426.

Grotkopp, E. \& Rejmánek, M. (2007) High seedling relative growth rate and specific leaf area are traits of invasive species: phylogenetically independent contrasts of woody angiosperms. American Journal of Botany, 94, 526-532.

Grotkopp, E., Rejmánek, M. \& Rost, T.L. (2002) Towards a causal explanation of plant invasiveness: seedling growth and life-history strategies of 29 Pine (Pinus) species. American Naturalist, 159, 396-419.

Hamilton, M.A., Murray, B.R., Cadotte, M.W., Hose, G.C., Baker, A.C., Harris, C.J. \& Licari, D. (2005) Life-history correlates of plant invasiveness at regional and continental scales. Ecology Letters, 8, 1066-1074.

Herron, P.M., Martine, C.T., Latimer, A.M. \& Leicht-Young, S.A. (2007) Invasive plants and their ecological strategies: prediction and explanation of woody plant invasion in New England. Diversity and Distribution, 13, 633644 .

Hosmer, D.W. \& Lemeshow, S. (2000) Applied Logistic Regression. John Wiley \& Sons, Inc, New York.

Kareiva, P., Parker, I.M. \& Pascual, M. (1996) Can we use experiments and models in predicting the invasiveness of genetically engineered organisms? Ecology, 77, 1670-1675.
Křivánek, M., Pyšek, P. \& Jarošik, V. (2006) Planting history and propagule pressure as predictors of invasion by woody species in a temperate region. Conservation Biology, 5, 1487-1498.

Küster, E.C., Kühn, I., Bruelheide, H. \& Klotz, S. (2008) Trait interactions help explain plant invasion success in the German flora. Journal of Ecology, 96, 860-868.

Lambdon, P.W., Pyšek, P., Basnou, C., Hejda, M. Aranoutsou, M., Essl, F. et al. (2008) Alien flora of Europe: species diversity, temporal trends, geographical patterns and research needs. Preslia, 80, 101-149.

Lockwood, J.L., Cassey, P. \& Blackburn, T. (2005) The role of propagule pressure in explaining species invasions. Trends in Ecology and Evolution, 20, 223-228.

Menard, S. (2000) Coefficients of determination for multiple logistic regression analysis. American Statistician, 54, 17-24.

Milbau, A. \& Stout, J.C. (2008) Factors associated with alien plants transitioning from casual, to naturalized, to invasive. Conservation Biology, 22, 308-317.

Moles, A.T., Gruber, M.A.M. \& Bonser, S.P. (2008) A new framework for predicting invasive plant species. Journal of Ecology, 96, 13-17.

Mulvaney, M. (2001) The effect of introduction pressure on the naturalization of ornamental woody plants in south-eastern Australia. Weed Risk Assessment (eds R.H. Groves, F.D. Panetta \& J.G. Virtue), pp. 186-193. CSIRO Publishing, Collingwood.

Nentwig, W. (2007) General conclusions, or what has to be done now? Biological Invasions, Ecological Studies 193 (ed. W. Nentwig), pp. 419-423. Springer-Verlag, Berlin.

Payne, R.W., Harding, S.A., Murray, D.A., Soutar, D.M., Baird, D.B., Welham, S.J., Kane, A.F., Gilmour, A.R., Thompson, R., Webster, R. \& Tunnicliffe, Wilson, G. (2005) The Guide to Genstat Release 8. Part 2: Statistics. VSN International, Oxford.

Pianka, E.R. (1970) On r- and K-selection. American Naturalist, 104, 592-597.

Pimentel, D., Lach, L., Zuniga, R. \& Morrison, D. (2000) Environmental and economic costs of nonindigenous species in the United States. Bioscience. 50, 53-65.

Prinzing, A., Durka, W., Klotz, S. \& Brandl, R. (2002) Which species become aliens? Evolutionary Ecology Research, 4, 385-405.

Pyšek, P. \& Jarošik, V. (2005) Residence time determines the distribution of alien plants. Invasive Plants: Ecological and Agricultural Aspects (ed. S. Inderjit), pp. 77-96. Birkhäuser Verlag, Basel.

Pyšek, P. \& Richardson, D.M. (2007) Traits associated with invasiveness in alien plants: where do we stand? Biological Invasions, Ecological Studies 193 (ed. W. Nentwig), pp. 97-126. Springer-Verlag, Berlin.

Pyšek, P., Sádlo,J., Mandák, B. \& Jarošik, V. (2003) Czech alien flora and the historical pattern of its formation: what came first to Central Europe. Oecologia, 135, 122-130.

Pyšek, P., Richardson, D.M. \& Williamson, M. (2004) Predicting and explaining plant invasions through analysis of source area floras: some critical considerations. Diversity and Distributions, 10, 179-187.

Reichard, S.H. \& Hamilton, C.W. (1997) Predicting invasions of woody plants introduced into North America. Conservation Biology, 11, 193-203.

Rejmánek, M. (1995) What makes a species invasive. Plant Invasions - General Aspects and Special Problems (eds P. Pyšek, P. Prach, M. Rejmánek \& M. Wade), pp. 3-13. Academic Publishing, Amsterdam.

Rejmánek, M. (1996) A theory of seed plant invasiveness: the first sketch. Biological Conservation, 78, 171-181.

Rejmánek, M. \& Richardson, D.M. (1996) What attributes make some plant species more invasive. Ecology, 77, 1655-1661

Richards, C.L., Bossdorf, O., Muth, N.Z., Gurevitch, J. \& Pigliucci, M. (2006) Jack of all trades, master of some? On the role of phenotypic plasticity in plant invasions. Ecology Letters, 9, 981-993.

Richardson, D.M. \& Pyšek, P. (2008) Fifty years of invasion ecology - the legacy of Charles Elton. Diversity and Distributions, 14, 161-168.

Richardson, D.M. \& Rejmánek, M. (2004) Conifers as invasive aliens: a globa survey and predictive framework. Diversity and Distributions, 10, 321-331.

Scott, J.K. \& Panetta, F.D. (1993) Predicting the Australian weed status of southern African plants. Journal of Biogeography, 20, 87-93.

Thuiller, W., Richardson, D.M., Rougert, M., Proches, S. \& Wilson, J.R.U. (2006) Interactions between environment, species traits, and human uses describe patterns of plant invasions. Ecology, 87, 1755-1769.

van Kleunen, M. \& Johnson, S.D. (2007) South African Iridaceae with rapid and profuse seedling emergence are more likely to become naturalized in other regions. Journal of Ecology, 95, 674-68

van Kleunen, M. \& Richardson, D.M. (2007) Invasion biology and conservation biology: time to join forces to explore the links between species traits and extinction risk and invasiveness. Progress in Physical Geography, 31, 447-450.

van Kleunen, M., Johnson, S.D. \& Fischer, M. (2007) Predicting naturalization of southern African Iridaceae in other regions. Journal of Applied Ecology, 44, 594-603. 
van Kleunen, M., Manning, J.C., Pasqualetto, V. \& Johnson, S.D. (2008) Phylogenetic independent associations between autonomous self-fertilization and plant invasiveness. American Naturalist, 171, 195-201.

Vitousek, P.M., D’Antonio, C.M., Loope, L.L., Rejmánek, M. \& Westbrooks, R. (1997) Introduced species: a significant component of human-caused global change. New Zealand Journal of Ecology, 21, 1-16.

Walther, G.-R., Post, E., Convey, P., Menzel, A., Parmesanii, C., Beebee,

T.J.C., Fromentin, J.-M., Hoegh-Guldberg, O. \& Bairlein, F. (2002) Ecological responses to recent climate change. Nature, 416, 389-395.
Wein, K. (1930) Die erste Einführung nordamerikanischer Gehölze in Europa. I. Mitteilungen der Deutschen Dendrologischen Gesellschaft, 42, 137-163 (in German).

Wein, K. (1931) Die erste Einführung nordamerikanischer Gehölze in Europa. II. Mitteilungen der Deutschen Dendrologischen Gesellschaft, 43, 95-154 (in German). Williamson, M. (1996) Biological Invasions. Chapman Hall, London. 